\title{
Principal Component Analysis on Morphological Variability of Critical Success Factors for Enterprise Resource Planning
}

\author{
Ayogeboh Epizitone ${ }^{1}$, Oludayo. O. Olugbara ${ }^{2}$ \\ ICT and Society Research Group, South Africa Luban Workshop \\ Durban University of Technology \\ Durban, South Africa
}

\begin{abstract}
The concept of critical success factors (CSFs) has been widely used as a measure to tackle the hurdles associated with numerous implementations of enterprise resource planning (ERP) systems. This study evaluates the morphological variability of CSFs using the analytical principal component analysis technique to identify principal components (PCs) that can be adopted for a successful ERP system implementation. The dataset of 205 CSFs from 127 different studies was evaluated for the morphological variability in those studies. According to the results, 66 PCs were identified and ranked accordingly. The first 49 PCs with eigenvalues greater than 1 accounted for $89.67 \%$ of the variability recorded. The first 6 PCs respectively accounted for $13.67 \%, 19.37 \%, 24.67 \%, 29.41 \%, 33.52 \%$ and $36.94 \%$ cumulative variations. In general, the graphical illustration of the study results show the palpable division between the taxonomic groups for 3 PCs.
\end{abstract}

Keywords-Enterprise resources; morphological variability; principal component; resource planning; success factor

\section{INTRODUCTION}

Critical success factors (CSFs) have been identified to be an essential precept for a successful ERP system implementation [1]. A critical success factor is a variable that has a significant impact on delivering a measurable improvement to project success [2]. The relevance of CSFs classification in ERP systems has been emphasised in various studies using different methods [1,3]. Certain authors, Hentschel, Leyh and Baumhauer [4] as well as Denolf, Trienekens, Wognum, van der Vorst and Omta [5], have postulated that despite the strong focus on avoiding failure in system implementation using CSFs approach, CSFs remain rarely researched. On the other hand, Saxena and McDonagh [6], have contended that CSFs remain the most-researched areas over the past years within the domain of enterprise systems.

However, despite this contention, there exists a consensus among researchers that CSF is a highly significant concept that can help address the inherent challenges associated with ERP system implementation [7]. Moreover, this has led to the identification of diverse CSFs in the literature. Consequently, the overarching objective of this study is to apply principal component analysis (PCA) to analyse morphological variability of CSFs for successful implementation of ERP systems. The realisation of the objective of this study affords the following distinctive contributions. An enhanced understanding of the concept of CSFs that acknowledges their morphological variability for an efficacious implementation of ERP systems. The application of a robust analytical method to provide valued acumen to the CSFs phenomena of ERP system implementation. The remainder of this paper is succinctly summarized as follows. The next section provides the background discussion with respect to the related literature. This is followed by the description of the material and methods of the study. Next is the presentation of results and discussion and the paper is briefly concluded.

\section{BACKGROUND}

The nature of CSFs has been reported in the literature to be inconsistent and repetitive, yielding the need for more analytical scientific methods [8-10]. Epizitone and Olugbara [11] highlighted this need by emphasising on the holistic nature of CSFs in different application settings. This view is further supported by the adoption of a mixed method research approach to tackle the complex phenomena of CSFs [12]. The determination of morphological variability of CSFs is a significant part of a successful implementation of an ERP project. The significance of CSFs classification has been emphasised in various related studies with a lot of attentions paid to the importance of CSFs and the success of ERP system implementations [9]. Consequently, the application of PCA to extract relevant information regarding CSFs from a large dimensional dataset is considered to enhance a deeper understanding of the intrinsic characteristics of CSFs [13].

PCA is a useful mathematical technique for emphasising variations and exposing hidden patterns in a dataset. It is predominantly applied for dimensionality reduction in application domains such as computer vision and pattern discovery in data mining [14]. It has been successfully used to specify principal components in varieties of datasets in many other areas of data science [14-18]. The technique has the potential to reveal essential characteristics while capturing the main structures of CSFs variability [19]. It is useful for discovering, reducing and identifying meaningful variables in a dataset. Hanci and Cebeci [15] have reported PCA to be a multivariate statistical technique with the capability of converting a lot of likely correlated factors into a set of smaller factors called principal components (PCs). The direction of the first $\mathrm{PC}$ is the same with the largest eigenvalue allied with its 
eigenvector. While the direction of the second PC is determined by the eigenvector, which is related to the second largest eigenvalue.

The PCA technique involves a mathematical procedure that is based on the eigen analysis, which computes eigenvalues and corresponding eigenvectors of a square symmetric matrix with sums of squares and cross products [20]. The paramount objective of this study as earlier stated is to apply the PCA technique to analyse morphological variability of CSFs for successful implementation of ERP systems. The analysis technique would help to identify different PCs for promoting ERP system adoption [21]. It is assumed that the results of this study will provide the knowledge of CSFs that is appropriate for use in a successful implementation of an ERP system.

\section{MATERIAL AND METHODS}

In this study, a total of 205 CSFs identified from 127 studies [22-27] was compiled and represented in a binary format displaying the feature of the identified variables for further analysis. The study dataset shown in Table S1 describes each factor as well as provides 205 qualitative CSFs and 127 quantitative instances that are suitable for PCA. The dataset was subjected to PCA to characterise the CSFs and identify the weight of each factor. The PCA technique was applied to a transformed dataset that was standardised into units of classes and attributes to determine the morphological variability. The number of PCs was determined using the minimal eigenvalue of unity called Kaiser criterion [28]. The dataset consisted of attributes 1 to 205 coded numerically as @ ATTRIBUTE F1F205, while the related papers investigated for the extraction of factors were coded as @ATTRIBUTE class (P1-P127). All statistical procedures for the evaluation of morphological variability were obtained using the IBM SPSS statistics version 25 and WEKA 3.8.3. These statistical tools mutually afford an added validation advantage in identifying variations among the CSFs for ERP system implementation. The focus was on their morphological variation as it influences implementation success whilst providing the chance to analyse more than one factors in association.

\section{RESUlTS AND DisCUSSION}

Table S2 illustrates the 66 PCs and 49 PCs identified by WEKA and SPSS with their corresponding eigenvalue, variance, and cumulative percentage. The WEKA statistical software identified 66 PCs with eigenvalue 28.015 to 0.518 , variance 13.667 to 0.253 and cumulative variance 13.666 to $95.205 \%$. Each component of the 49 PCs identified by the IBM SPSS accounted for the following percentage range: eigenvalue 28.015 to 1.007 , variance 13.667 to 0.491 and cumulative variance 13.666 to 89.199 . The 49 PCs identified by the SPSS tool also featured in the 66 PCs identified by the WEKA software and they constitute the first 49 components in the WEKA result. These 49 components only consider the eigenvalues that are greater than unity as in other studies that applied PCA to different practical problems [28-30]. However, the 49 PCs had eigenvalue ranging from 28.015 for the first component to 1.007 for the last component. In addition, the 17 subsequent PCs had eigenvalues less than unity falling in the range of 0.962 to 0.517 for the PC 50 and PC 66, respectively.
Fig. 1 shows the ranking of the 66 PCs with the first six components respectively having the following scores: $86.33 \%$, 80.00\%, 75.36\%, 70.59\%, 66.45\% and 63.06\%.

The Vendor (F1) extraction value for PC represents the lowest value of 0.631 , while the maximum extracted values are for F31-Professional training services, F32-Setting realistic deadlines, F37-User participation in defying new processes, F58-Deep understanding strategy, F60-Former major change experience, F81-Business change is first to be considered, F85Level of implementation acceleration, F139- Opportunities for growth and F146-Data model is compatible with data requirements. It can be noted from the first component that these factors loadings were integrated to account for the high eigenvalue.

The first 6 PCs cumulative variations are 13.67\%, 19.37\%, $24.67 \%, 29.41 \%$, 33.52\% and $36.94 \%$ respectively as shown in Table I. These PCs can be seen to be distinctively illustrated by screen plot in Fig. 2, while Fig. 3 represents the component transformation matrix and Fig. 4 is the component matrix. These results illustratively provide the appropriate visualisation of the CSFs morphological variability that justifies the significance of these factors and their interpretations. The communalities shown in Table II, present each factor loading used for extraction that can be seen within a range of 0.631 minimum to 0.995 maximum for the component extracted. Table II further shows the result of the analysis presented for the communality showing the contribution of each factor.

The PC one (PC1) has an eigenvalue of 28.015, which explains 13.667 as the total variance with the same value for the cumulative variance. Taking into composition the contributions of individual weighted factor values for the PC occurring from the factors in Table II. The contribution of 10 factors can be seen in the table identifying different groups for the 6 PCs (Table I). Fig. 5 shows the first six components in rotated space. The contribution can further be seen in Table S3. The first group for PC 1 includes CSF such as Business change is first to be considered with eigenvector of 0.166 variation that reflects environment to the level of implementation acceleration and using ERP to fulfil cross-functional areas with 0.15 variation. This component presents the largest variability in the dataset as compared to the subsequent components [15, 29].

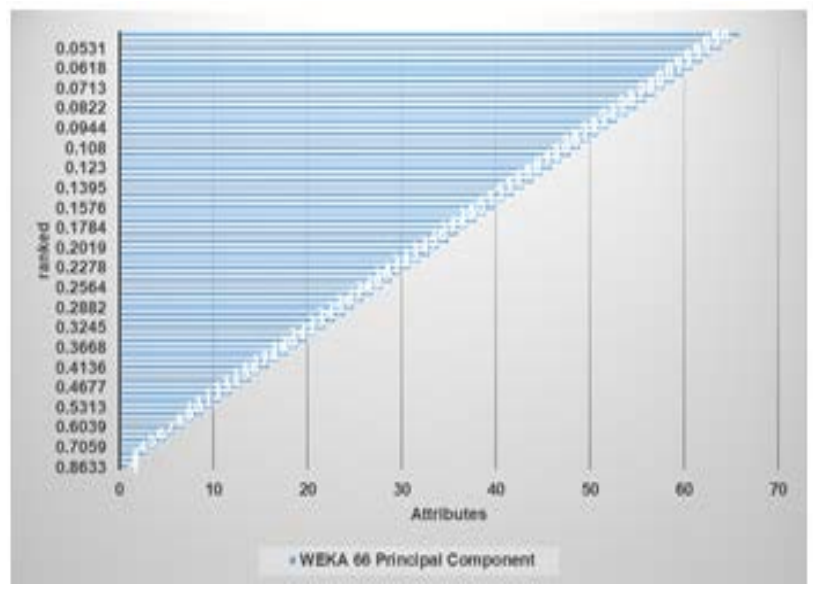

Fig. 1. Ranking of 66 PCs. 


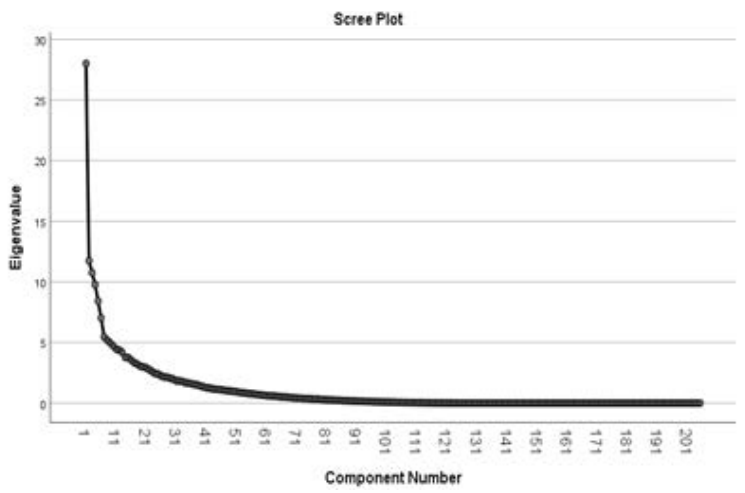

Fig. 2. Scree Plot of the PCs.

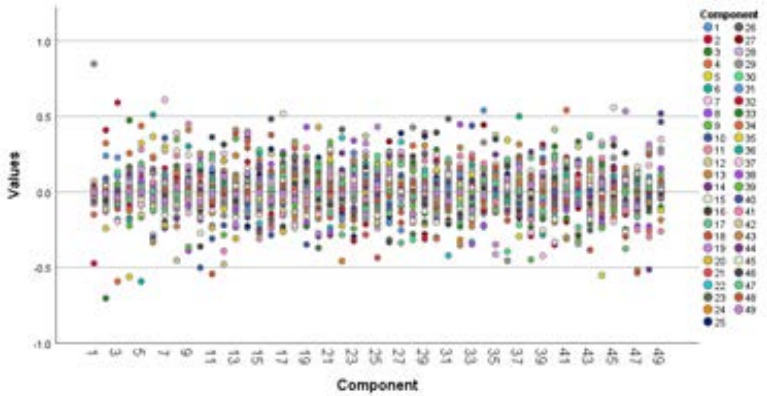

Fig. 3. Component Transformation Matrix for the Identified Components.

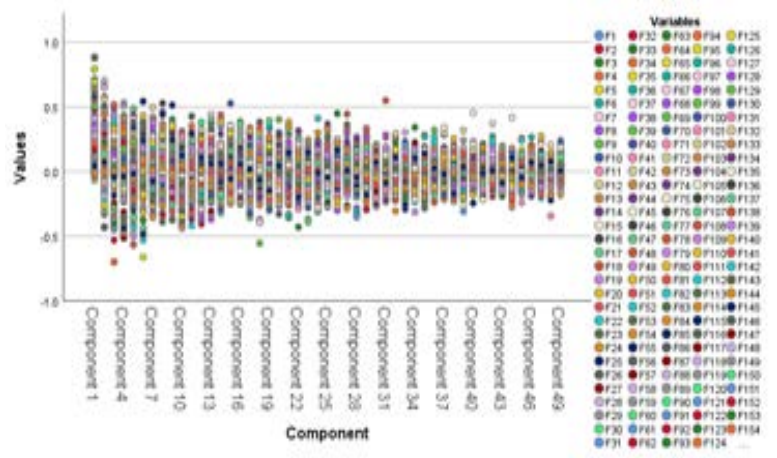

Fig. 4. Component Matrix of 49 PCs.

TABLE I. FIRST SIX COMPONENTS 10 FACTOR LOADINGS

\begin{tabular}{|c|c|}
\hline PC1 & $\begin{array}{l}0.166 \mathrm{~F} 81+0.166 \mathrm{~F} 37+0.166 \mathrm{~F} 146+0.166 \mathrm{~F} 32+0.166 \mathrm{~F} 60 \\
+0.166 \mathrm{~F} 31+0.166 \mathrm{~F} 85+0.166 \mathrm{~F} 58+0.166 \mathrm{~F} 139+0.15 \mathrm{~F} 117 \ldots\end{array}$ \\
\hline PC2 & $\begin{array}{l}0.205 F 118+0.193 F 133+0.189 F 178+0.169 F 13+0.162 F 132 \\
+0.148 F 173+0.145 F 66+0.143 F 14+0.14 \text { F41+0.136F131 } \ldots\end{array}$ \\
\hline PC3 & $\begin{array}{l}-0.213 F 128-0.213 F 181-0.213 F 184-0.162 F 182+0.157 F 17 \\
+0.157 F 171+0.148 F 14-0.137 F 114+0.134 F 18-0.134 F 121 \ldots\end{array}$ \\
\hline PC4 & $\begin{array}{l}-0.169 F 149+0.165 F 177-0.161 F 88+0.159 F 125+0.159 F 20 \\
+0.159 F 117+0.149 F 94+0.149 F 92+0.148 F 87+0.144 F 93 \ldots\end{array}$ \\
\hline PC5 & $\begin{array}{l}-0.195 F 17-0.195 F 171-0.172 F 18-0.172 F 109+0.168 F 137 \\
+0.167 F 134-0.161 F 15+0.151 F 74-0.15 F 172+0.149 F 21 \ldots\end{array}$ \\
\hline PC6 & $\begin{array}{l}0.25 \text { F95-0.205F77-0.204F175+0.2 F82+0.184F97+0.183F145 } \\
+0.171 \text { F91+0.164F107-0.164F170-0.146F28... }\end{array}$ \\
\hline
\end{tabular}
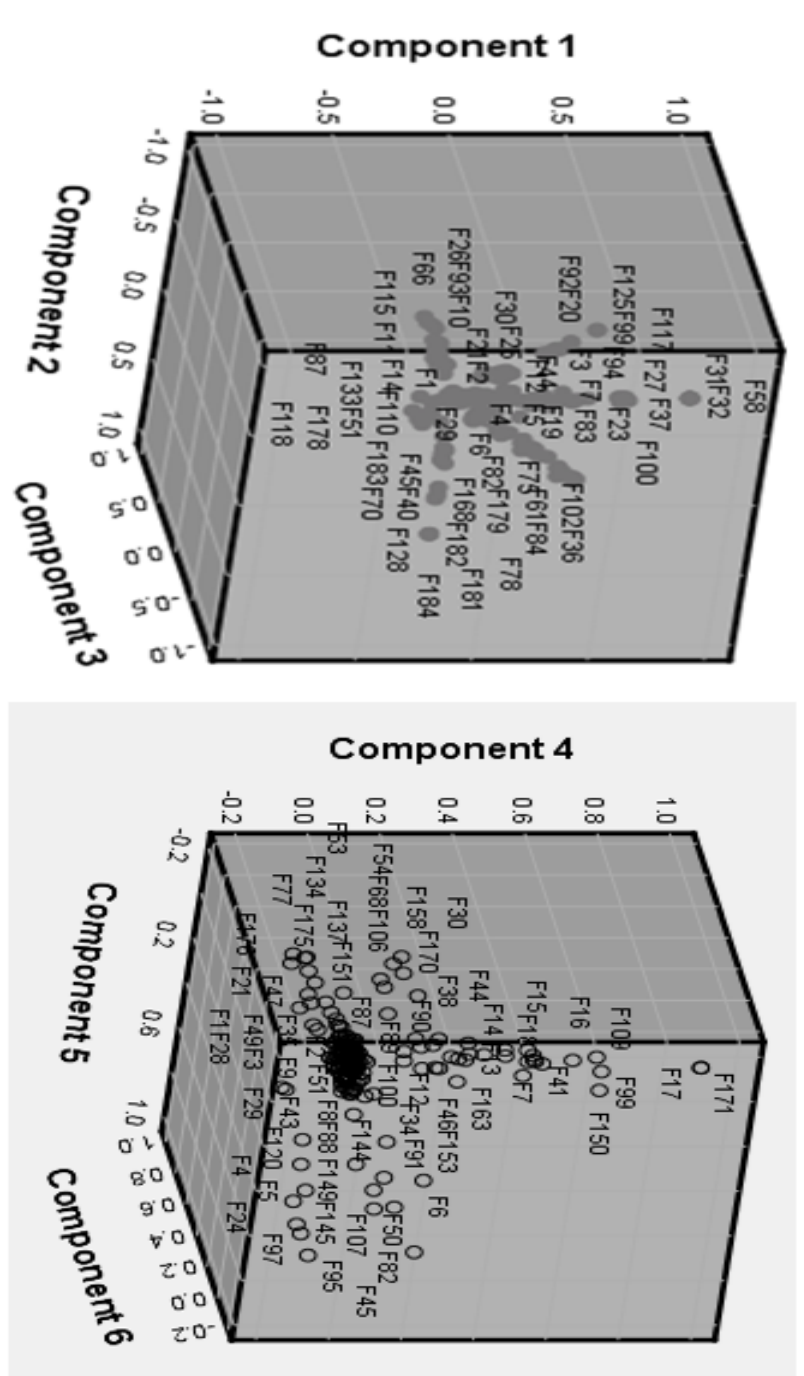

Fig. 5. Principal Component Plot in Rotated Space Graph for the First SixComponent (PC1 - PC6).

Several other groups were identified that consisted of different variational contributions from CSFs. In the second PC, the only factor that reached the eigenvector value of 0.205 is End users' attitudes (F118). The second component also had high eigenvector for the ERP easy to learn (Learnability/ awareness (F133): 0.193, Availability of reliable data networks (F178): 0.189, Assign responsibility/Clear roles and responsibilities (F13), 0.169 and ERP usefulness (F132) 0.162.The highest eigenvector for PC three was achieved by Defined project miles' stones (F17): 0.157, Coordinate project activities (F171): 0.157 and subsequently Social influence (F177): 0.165. For PC four, software configuration (F137): 0.168, Vanilla ERP (F134): 0.167 for PC five and Education on new business processes (F95):0.25, Architecture choices (F82): 0.2 for PC six. 
TABLE II. COMMUNALITY

\begin{tabular}{|c|c|c|c|c|c|c|c|c|c|c|c|}
\hline Factors & Initial(I) & Extraction & & & & & & & & & \\
\hline F1 & 1.000 & 0.631 & F53 & 1.000 & 0.874 & F105 & 1.000 & 0.881 & F157 & 1.000 & 0.847 \\
\hline F2 & 1.000 & 0.833 & F54 & 1.000 & 0.869 & F106 & 1.000 & 0.840 & F158 & 1.000 & 0.860 \\
\hline F3 & 1.000 & 0.949 & F55 & 1.000 & 0.969 & F107 & 1.000 & 0.821 & F159 & 1.000 & 0.856 \\
\hline F4 & 1.000 & 0.898 & F56 & 1.000 & 0.870 & F108 & 1.000 & 0.929 & F160 & 1.000 & 0.963 \\
\hline F5 & 1.000 & 0.873 & F57 & 1.000 & 0.838 & F109 & 1.000 & 0.983 & F161 & 1.000 & 0.887 \\
\hline F6 & 1.000 & 0.926 & F58 & 1.000 & 0.995 & F110 & 1.000 & 0.814 & F162 & 1.000 & 0.903 \\
\hline F7 & 1.000 & 0.887 & F59 & 1.000 & 0.791 & F111 & 1.000 & 0.862 & F163 & 1.000 & 0.874 \\
\hline F8 & 1.000 & 0.816 & F60 & 1.000 & 0.995 & F112 & 1.000 & 0.814 & F164 & 1.000 & 0.886 \\
\hline F9 & 1.000 & 0.911 & F61 & 1.000 & 0.881 & F113 & 1.000 & 0.863 & F165 & 1.000 & 0.855 \\
\hline F10 & 1.000 & 0.881 & F62 & 1.000 & 0.928 & F114 & 1.000 & 0.914 & F166 & 1.000 & 0.958 \\
\hline F11 & 1.000 & 0.950 & F63 & 1.000 & 0.778 & F115 & 1.000 & 0.816 & F167 & 1.000 & 0.776 \\
\hline F12 & 1.000 & 0.862 & F64 & 1.000 & 0.960 & F116 & 1.000 & 0.902 & F168 & 1.000 & 0.817 \\
\hline F13 & 1.000 & 0.860 & F65 & 1.000 & 0.895 & F117 & 1.000 & 0.985 & F169 & 1.000 & 0.886 \\
\hline F14 & 1.000 & 0.962 & F66 & 1.000 & 0.869 & F118 & 1.000 & 0.983 & F170 & 1.000 & 0.851 \\
\hline F15 & 1.000 & 0.751 & F67 & 1.000 & 0.827 & F119 & 1.000 & 0.885 & F171 & 1.000 & 0.974 \\
\hline F16 & 1.000 & 0.910 & F68 & 1.000 & 0.829 & F120 & 1.000 & 0.847 & F172 & 1.000 & 0.871 \\
\hline F17 & 1.000 & 0.974 & F69 & 1.000 & 0.982 & F121 & 1.000 & 0.970 & F173 & 1.000 & 0.985 \\
\hline F18 & 1.000 & 0.969 & F70 & 1.000 & 0.987 & F122 & 1.000 & 0.862 & F174 & 1.000 & 0.817 \\
\hline F19 & 1.000 & 0.793 & F71 & 1.000 & 0.841 & F123 & 1.000 & 0.908 & F175 & 1.000 & 0.875 \\
\hline F20 & 1.000 & 0.985 & F72 & 1.000 & 0.884 & F124 & 1.000 & 0.930 & F176 & 1.000 & 0.872 \\
\hline F21 & 1.000 & 0.866 & F73 & 1.000 & 0.930 & F125 & 1.000 & 0.985 & F177 & 1.000 & 0.950 \\
\hline F22 & 1.000 & 0.902 & F74 & 1.000 & 0.854 & F126 & 1.000 & 0.888 & F178 & 1.000 & 0.947 \\
\hline F23 & 1.000 & 0.890 & F75 & 1.000 & 0.928 & F127 & 1.000 & 0.838 & F179 & 1.000 & 0.958 \\
\hline F24 & 1.000 & 0.887 & F76 & 1.000 & 0.823 & F128 & 1.000 & 0.984 & F180 & 1.000 & 0.963 \\
\hline F25 & 1.000 & 0.809 & F77 & 1.000 & 0.890 & F129 & 1.000 & 0.960 & F181 & 1.000 & 0.984 \\
\hline F26 & 1.000 & 0.889 & F78 & 1.000 & 0.861 & F130 & 1.000 & 0.947 & F182 & 1.000 & 0.951 \\
\hline F27 & 1.000 & 0.896 & F79 & 1.000 & 0.880 & F131 & 1.000 & 0.907 & F183 & 1.000 & 0.862 \\
\hline F28 & 1.000 & 0.912 & F80 & 1.000 & 0.855 & F132 & 1.000 & 0.960 & F184 & 1.000 & 0.984 \\
\hline F29 & 1.000 & 0.824 & F81 & 1.000 & 0.995 & F133 & 1.000 & 0.918 & F185 & 1.000 & 0.877 \\
\hline F30 & 1.000 & 0.895 & F82 & 1.000 & 0.923 & F134 & 1.000 & 0.886 & F186 & 1.000 & 0.719 \\
\hline F31 & 1.000 & 0.995 & F83 & 1.000 & 0.902 & F135 & 1.000 & 0.797 & F187 & 1.000 & 0.830 \\
\hline F32 & 1.000 & 0.995 & F84 & 1.000 & 0.942 & F136 & 1.000 & 0.831 & F188 & 1.000 & 0.981 \\
\hline F33 & 1.000 & 0.885 & F85 & 1.000 & 0.995 & F137 & 1.000 & 0.892 & F189 & 1.000 & 0.934 \\
\hline F34 & 1.000 & 0.835 & F86 & 1.000 & 0.960 & F138 & 1.000 & 0.854 & F190 & 1.000 & 0.869 \\
\hline F35 & 1.000 & 0.829 & F87 & 1.000 & 0.876 & F139 & 1.000 & 0.995 & F191 & 1.000 & 0.890 \\
\hline F36 & 1.000 & 0.874 & F88 & 1.000 & 0.863 & F140 & 1.000 & 0.785 & F192 & 1.000 & 0.843 \\
\hline F37 & 1.000 & 0.995 & F89 & 1.000 & 0.809 & F141 & 1.000 & 0.980 & F193 & 1.000 & 0.932 \\
\hline F38 & 1.000 & 0.846 & F90 & 1.000 & 0.896 & F142 & 1.000 & 0.972 & F194 & 1.000 & 0.885 \\
\hline F39 & 1.000 & 0.868 & F91 & 1.000 & 0.829 & F143 & 1.000 & 0.809 & F195 & 1.000 & 0.796 \\
\hline F40 & 1.000 & 0.914 & F92 & 1.000 & 0.979 & F144 & 1.000 & 0.823 & F196 & 1.000 & 0.947 \\
\hline F41 & 1.000 & 0.905 & F93 & 1.000 & 0.921 & F145 & 1.000 & 0.886 & F197 & 1.000 & 0.925 \\
\hline F42 & 1.000 & 0.839 & F94 & 1.000 & 0.979 & F146 & 1.000 & 0.995 & F198 & 1.000 & 0.970 \\
\hline F43 & 1.000 & 0.806 & F95 & 1.000 & 0.926 & F147 & 1.000 & 0.887 & F199 & 1.000 & 0.790 \\
\hline F44 & 1.000 & 0.903 & F96 & 1.000 & 0.844 & F148 & 1.000 & 0.841 & F200 & 1.000 & 0.878 \\
\hline F45 & 1.000 & 0.819 & F97 & 1.000 & 0.909 & F149 & 1.000 & 0.928 & F201 & 1.000 & 0.832 \\
\hline F46 & 1.000 & 0.835 & F98 & 1.000 & 0.856 & F150 & 1.000 & 0.969 & F202 & 1.000 & 0.972 \\
\hline F47 & 1.000 & 0.867 & F99 & 1.000 & 0.984 & F151 & 1.000 & 0.878 & F203 & 1.000 & 0.972 \\
\hline F48 & 1.000 & 0.902 & F100 & 1.000 & 0.941 & F152 & 1.000 & 0.822 & F204 & 1.000 & 0.904 \\
\hline F49 & 1.000 & 0.867 & F101 & 1.000 & 0.772 & F153 & 1.000 & 0.812 & F205 & 1.000 & 0.883 \\
\hline F50 & 1.000 & 0.883 & F102 & 1.000 & 0.977 & F154 & 1.000 & 0.775 & & & \\
\hline F51 & 1.000 & 0.938 & F103 & 1.000 & 0.817 & F155 & 1.000 & 0.972 & & & \\
\hline F52 & 1.000 & 0.839 & F104 & 1.000 & 0.880 & F156 & 1.000 & 0.936 & & & \\
\hline
\end{tabular}


These results report the presence of great morphological variability for some of the CSFs presenting specification of the CSFs diversification of ERP system implementation based on the taxonomy of the groups possibly identified by the selection of these CSFs. In this paper, we have explained the morphological variability and tried to model the CSFs to diverse components that are relevant to ERP system implementation. It can be seen from these results that taxonomic groups were conceivably attained by selecting these features. Azadeh, Afshari-Mofrad and Khalojini [30] and García, Rivera and Iniesta [31] applied PCA to their studies to characterised CSFs. The current study explicates on the diversity of CSFs variability based on different identity groups. Many studies undertaken on CSFs have selected certain CSFs to contextualise their results. However, results of the current study are attained from the inclusion of all the identified CSFs to provide a holistic nature of CSFs with different morphology. A similar approach to Ahmad, Haleem and Syed [22], study where all CSFs identified were retained for further analysis [3], characterised CSFs using a hybrid approached of PCA and impact factor analysis to identify, validate, rank and classify factors as critical, active, inert and reactive. Bhatti [32] applied PCA on a smaller dataset consisting of data from 53 inputs, using the reliability and validity scale to explain and characterise 11 CSFs with eigenvalue greater than 1 that only assimilation factor loads greater than 0.5. Madapusi and Ortiz [33] report findings on ERP, discussing two factors that account for 50.315 of the variability following a lesser Cronbach alpha statistic of 0.60 as compared to Bhatt [32] who used 0.75 .

The projection of the 205 CSFs morphology in the twodimensional graph of the component plot is shown in Fig. 3 and Fig. 4. The first, second and third PC coordinates of the PCA is realised using the morphological data accounted for $24.67 \%$ of the diversity observed (Fig. 3). While the subsequent three PCs four, five and six in Fig. 4 accounted for $12.30 \%$. Overall, these displays denote an obvious division between taxonomic groups of CSFs relevant for the success of ERP system implementation.

\section{CONCLUSION}

Employing different markers of the CSFs, diversification was estimated by exploring the morphological attributes that provide essential preliminary method for gauging different CSFs while concurrently elucidating their performance under successful implementation. The substantial knowledge presented by the results of this study is the CSFs variability applicable to various implementations of ERP systems. In this study, 205 different CSFs were analysed by using data obtained from 127 studies presenting different morphological findings of CSFs. The low variability of the first six principal components demonstrates that the diversity of the pool was significantly with the highest CSFs having eigenvectors not limited to values such as $0.25,0.205,0.193,0.169$ and 0.157 .

The results of this study provide an important contribution to the ERP CSFs body of knowledge with a special attention paid to the morphological features of a disparate model from several morphological taxonomies of the identified CSFs using a robust analytical method. The study results can help practitioners not to neglect any CSF, rather they should attach significant consideration to their roles in ensuring a successful implementations of ERP systems.

\section{ACKNOWLEDGMENT}

The first author would like to thank her fellow researchers for their inspirations and the Durban University of Technology for the support provided during the study.

\section{REFERENCES}

[1] N. Ahmed, A. A. Shaikh, and M. Sarim, "Critical success factors plays a vital role in ERP implementation in developing countries: An exploratory study in Pakistan," International Journal of Advanced Computer Science And Applications, vol. 8, no. 10, pp. 21-29, 2017.

[2] Z. Alias, E. Zawawi, K. Yusof, and N. Aris, "Determining critical success factors of project management practice: A conceptual framework," Procedia-Social and Behavioral Sciences, vol. 153, pp. 61-69, 2014.

[3] B. M. Kalema, O. O. Olugbara, and R. M. Kekwaletswe, "Identifying critical success factors: the case of ERP systems in higher education," The African Journal of Information Systems, 6(3), p.1, 2014.

[4] R. Hentschel, C. Leyh, and T. Baumhauer, "Critical success factors for the implementation and adoption of cloud services in SMEs." In Proceedings of the 52nd Hawaii International Conference on System Sciences.

[5] J. M. Denolf, J. H. Trienekens, P. N. Wognum, J. G. van der Vorst, and S. O. Omta, "Towards a framework of critical success factors for implementing supply chain information systems," Computers in industry, vol. 68, pp. 16-26, 2015.

[6] D. Saxena, and J. McDonagh, "Yet another 'list'of critical success 'factors' for enterprise systems: Review of empirical evidence and suggested research directions." In The UK Academy for Information Systems, UK Academy of Information Systems Conference.

[7] C. Leyh, "Critical success factors for ERP projects in small and mediumsized enterprises-The perspective of selected German SMEs." In 2014 Federated Conference on Computer Science and Information Systems (pp. 1181-1190). IEEE, pp. 1181-1190.

[8] R. C. Thompson, O. O. Olugbara, and A. Singh, "Deriving critical success factors for implementation of enterprise resource planning systems in higher education institution," African Journal of Information Systems, vol. 10, no. 1, 2018.

[9] S. Dezdar, and A. Sulaiman, "Successful enterprise resource planning implementation: taxonomy of critical factors,” Industrial Management \& Data Systems, vol. 109, no. 8, pp. 1037-1052, 2009.

[10] S. Finney, and M. Corbett, "ERP implementation: a compilation and analysis of critical success factors," Business Process Management Journal, vol. 13, no. 3, pp. 329-347, 2007.

[11] A. Epizitone, and O. O. Olugbara, "Critical success factors for ERP system implementation to support financial functions," Academy of Accounting and Financial Studies Journal, vol. 23, no. 6, pp. 1-11, 2019.

[12] A. Epizitone, and O. O. Olugbara, "Mixed method approach to determination critical success factors for successful financial ERP system implementation,” Academy of Accounting and Financial Studies Journal, vol. 24, no. 2, pp. 1-10, 2020.

[13] F. Tang, and H. Tao, "Binary principal component analysis." In BMVC, pp. 377-386.

[14] H. Li, "Multivariate time series clustering based on common principal component analysis," Neurocomputing, vol. 349, pp. 239-247, 2019.

[15] F. Hanci, and E. Cebeci, "Determination of morphological variability of different pisum genotypes using principal component analysis," Legume Research-An International Journal, vol. 42, no. 2, pp. 162-167, 2019.

[16] H. Li, "Accurate and efficient classification based on common principal components analysis for multivariate time series," Neurocomputing, vol. 171, pp. 744-753, 2016.

[17] Z.-X. Li, J.-S. Guo, X.-B. Hui, and F.-F. Song, "Dimension reduction method for multivariate time series based on common principal component,” Control and Decision, vol. 28, no. 4, pp. 531-536, 2013. 
[18] R. Karayel, and H. Bozoglu, "Determination of morphological variability of local pea genotypes," Ekin Journal of Crop Breeding and Genetics, vol. 1, no. 2, pp. 56-64, 2015.

[19] C. R. Bern, K. Walton-Day, and D. L. Naftz, "Improved enrichment factor calculations through principal component analysis: Examples from soils near breccia pipe uranium mines, Arizona, USA,” Environmental Pollution, vol. 248, pp. 90-100, 2019.

[20] M. A. Espósito, L. A. Milanesi, E. Martin, V. Cravero, A. Lopez, and E. Cointry, "Principal component analysis based on morphological characters in pea (Pisum sativum L.),” Int. J. Plant Breed, vol. 1, no. 2, pp. 135-137, 2007.

[21] A. P. Chan, D. C. Ho, and C. Tam, "Design and build project success factors: multivariate analysis," Journal of construction engineering and management, vol. 127, no. 2, pp. 93-100, 2001.

[22] N. Ahmad, A. Haleem, and A. A. Syed, "Compilation of critical success factors in implementation of enterprise systems: a study on Indian organisations," Global Journal of Flexible Systems Management, vol. 13, no. 4, pp. 217-232, 2012.

[23] F. Fui-Hoon Nah, J. Lee-Shang Lau, and J. Kuang, "Critical factors for successful implementation of enterprise systems," Business process management journal, vol. 7, no. 3, pp. 285-296, 2001.

[24] F. F.-H. Nah, and S. Delgado, "Critical success factors for enterprise resource planning implementation and upgrade," Journal of Computer Information Systems, vol. 46, no. 5, pp. 99-113, 2006.

[25] C. Leyh, "Critical success factors for ERP projects in small and mediumsized enterprises - the perspective of selected ERP system vendors," Multidimensional Views on Enterprise Information Systems, pp. 7-22: Springer, 2016.

\section{SUPPLEMENTARY DOCUMENTS}

PRINCIPAL COMPONENT ANALYSIS ON MORPHOLOGICAL VARIABILITY OF CRITICAL SUCCESS FACTORS FOR ENTERPRISE RESOURCE PLANNING

TABLE SI. QUALITATIVE AND QUANTITATIVE ERP CSFS FOR PCA

\begin{tabular}{|c|c|c|}
\hline CSF Factors & Description & Occurrences \\
\hline F1 & Vendor & 4 \\
\hline F2 & Selection of appropriate vendor & 5 \\
\hline F3 & ERP vendor characteristics /reputation & 4 \\
\hline F4 & Partnership with vendor & 26 \\
\hline F5 & Vendor support & 33 \\
\hline F6 & Use of vendors' tools & 17 \\
\hline F7 & Keeping suppliers and customers informed & 5 \\
\hline F8 & Project Management & 71 \\
\hline F9 & Project leader & 9 \\
\hline F10 & Appointment \& availability of competent project manager & 4 \\
\hline F11 & project manager /Full time & 8 \\
\hline F12 & Scope creep Management (Detail schedule) & 19 \\
\hline F13 & Assign responsibility/ Clear roles \& responsibilities & 7 \\
\hline F14 & control project scope & 6 \\
\hline F15 & Evaluate any propose change & 3 \\
\hline F16 & Control and assess scope expansion requests/ assessment & 3 \\
\hline F17 & Define project miles stones & 1 \\
\hline F18 & Set realistic milestone and end dates & 3 \\
\hline F19 & Knowledge transfer management & 9 \\
\hline F20 & Management of conflicts & 2 \\
\hline F21 & Management of legacy systems & 18 \\
\hline F22 & Clear and defined project plan & 4 \\
\hline F23 & Planning required upgrades & 2 \\
\hline F24 & Management of expectations & 21 \\
\hline F25 & Management of risks & 14 \\
\hline F26 & Effective project management methodology & 7 \\
\hline F27 & Project tracking & 1 \\
\hline
\end{tabular}




\begin{tabular}{|c|c|c|}
\hline F28 & Total quality management approach & 9 \\
\hline F29 & Interdepartmental communication and cooperation & 81 \\
\hline F30 & $\begin{array}{l}\text { Open and honest communication (Targeted and effective communication, among stakeholders, } \\
\text { expectations communicated at all level and progress communication) }\end{array}$ & 15 \\
\hline F31 & Professional training services & 1 \\
\hline F32 & Setting realistic deadlines & 1 \\
\hline F33 & Project Management to implement project plan & 3 \\
\hline F34 & Change management & 70 \\
\hline F35 & Change management program & 18 \\
\hline F36 & Understanding the political structure (Political influence) & 4 \\
\hline F37 & User participation in defying new processes & 1 \\
\hline F38 & Understanding the organizational culture / (norms, values \& beliefs) & 36 \\
\hline F39 & Developing a culture of continuous improvement & 5 \\
\hline F40 & National culture & 3 \\
\hline F41 & Recognizing the need for change & 4 \\
\hline F42 & Commitment to change -perseverance and determination & 4 \\
\hline F43 & Project team competence (formulation, composition and involvement) & 67 \\
\hline F44 & Team finest cross functional knowledge /small internal team & 11 \\
\hline F45 & Trust between various shareholders & 5 \\
\hline F46 & Good relations between project team and users (Partnership, trust, risk-sharing and incentives) & 14 \\
\hline F47 & Team morale and motivation & 18 \\
\hline F48 & Full time team members & 8 \\
\hline F49 & Balanced and cross functional project team & 16 \\
\hline F50 & Allocating valuable resources/Dedicating resources & 25 \\
\hline F51 & Culture of resistance/ enabling constraints & 8 \\
\hline F52 & Counselling to staff to minimize resistance to change & 6 \\
\hline F53 & Staff retention & 6 \\
\hline F54 & Empowered decision makers & 18 \\
\hline F55 & Work time schedule & 4 \\
\hline F56 & Performance tied to compensation & 7 \\
\hline F57 & Availability of qualified implementation team & 4 \\
\hline F58 & Deep understanding strategy & 1 \\
\hline F59 & Organizational characteristics & 5 \\
\hline F60 & Former major change experience & 1 \\
\hline F61 & Having in place advanced technology & 4 \\
\hline F62 & Former major IT change experience/Previous organization’s experience with complex IS & 3 \\
\hline F63 & Interdepartmental coordination/ company wide & 9 \\
\hline F64 & Organization transformation and software migration & 1 \\
\hline F65 & Clear organizational strategy & 7 \\
\hline F66 & Organization encouragement of continuous learning & 2 \\
\hline F67 & Organization structure & 16 \\
\hline F68 & Implementation strategy & 16 \\
\hline F69 & Project definition and organization & 1 \\
\hline F70 & Implementation promotion & 2 \\
\hline F71 & Consultant's domain knowledge \& experience & 7 \\
\hline F72 & Appointment of consultant/ external consultant involve in implementation (third party) & 12 \\
\hline F73 & Managing consultants & 3 \\
\hline F74 & Use of consultants (Consultant selection and relationship) & 42 \\
\hline F75 & Decision making process style/Strategic Decision making & 7 \\
\hline F76 & Focused performance measures plan & 5 \\
\hline F77 & Planning the cost of ERP implementation-Project cost planning and management & 11 \\
\hline F78 & Regard as a technological, business, and organizational project & 8 \\
\hline F79 & Alignment between business strategy and IT strategy & 17 \\
\hline F80 & Ensuring fair time to fulfil the implementation & 6 \\
\hline F81 & Business change is first to be considered & 1 \\
\hline F82 & Architecture choices & 10 \\
\hline
\end{tabular}




\begin{tabular}{|c|c|c|}
\hline F83 & $\begin{array}{l}\text { Functional requirements are clearly defined before deciding on ERP adaptation/country } \\
\text { related/carefully defined information and system requirement }\end{array}$ & 9 \\
\hline F84 & Continues focus on organizational resistance & 4 \\
\hline F85 & Level of implementation acceleration & 1 \\
\hline F86 & Implementation approach & 1 \\
\hline F87 & Implementer's domain knowledge \& experience & 3 \\
\hline F88 & Project champion & 49 \\
\hline F89 & Education and training & 58 \\
\hline F90 & Education and training to technical staff /IT workforce re-skilling & 21 \\
\hline F91 & Education and training to end users & 48 \\
\hline F92 & Education on future business processes & 3 \\
\hline F93 & Adequate training to the implementation team & 2 \\
\hline F94 & Developing a clear education and training plan & 3 \\
\hline F95 & Education on new business processes & 11 \\
\hline F96 & Top management support & 105 \\
\hline F97 & Management and project steering committees & 17 \\
\hline F98 & management leadership & 10 \\
\hline F99 & Willingness to become involved & 2 \\
\hline F100 & Developing an understanding of the needs, capabilities \& IT limitations & 2 \\
\hline F101 & Exhibiting strong commitment & 4 \\
\hline F102 & Resolving political conflicts (Political influence) & 3 \\
\hline F103 & Willingness to adopt modern technologies/Adaption Mechanism & 5 \\
\hline F104 & dedicated staff of vendor and institute for implementation & 4 \\
\hline F105 & Financial budget /funding Model & 16 \\
\hline F106 & Business vision & 37 \\
\hline F107 & Project mission /goals (Clear Goals and Objective) & 42 \\
\hline F108 & beliefs on ERP (management, users, teams and managers)/ Perception & 5 \\
\hline F109 & Justification for investment in ERP (investment plan) & 2 \\
\hline F110 & BPR & 79 \\
\hline F111 & User involvement & 38 \\
\hline F112 & User participation in the overall process approach & 11 \\
\hline F113 & User uses the system according to guidance & 6 \\
\hline F114 & Users' trust & 2 \\
\hline F115 & Key users' business knowledge & 2 \\
\hline F116 & Appointment \& availability of competent key users & 3 \\
\hline F117 & Using ERP to fulfil cross functional areas & 2 \\
\hline F118 & End users' attitudes & 3 \\
\hline F119 & ERP System & 4 \\
\hline F120 & Level of Customization & 43 \\
\hline F121 & System flexibility to changing conditions & 3 \\
\hline F122 & System integration & 16 \\
\hline F123 & Systems reliability & 5 \\
\hline F124 & System interoperability & 1 \\
\hline F125 & System cross functionality & 2 \\
\hline F126 & System testing & 13 \\
\hline F127 & System quality & 7 \\
\hline F128 & Systems Changes and Upgrade & 1 \\
\hline F129 & System support & 2 \\
\hline F130 & ERP Version & 1 \\
\hline F131 & ERP ease of use/complexity & 7 \\
\hline F132 & ERP usefulness & 5 \\
\hline F133 & ERP easy to learn (Learnability/ awareness) & 3 \\
\hline F134 & Vanilla ERP & 10 \\
\hline F135 & Suitability of software and hardware considerations & 9 \\
\hline F136 & IT Infrastructure & 32 \\
\hline F137 & software configuration & 15 \\
\hline
\end{tabular}




\begin{tabular}{|c|c|c|}
\hline F138 & Environment & 7 \\
\hline F139 & Opportunities for growth & 1 \\
\hline F140 & Competition in industry/trend & 7 \\
\hline F141 & External/stakeholder pressure & 3 \\
\hline F142 & Competitors' adoption of ERP & 2 \\
\hline F143 & Uncertainty about environment & 4 \\
\hline F144 & Data Management & 24 \\
\hline F145 & Data analysis Plan & 14 \\
\hline F146 & Data model is compatible with data requirements & 1 \\
\hline F147 & Data quality control & 7 \\
\hline F148 & Developing a plan for migrating and cleaning up data & 5 \\
\hline F149 & Data conversion Plan & 20 \\
\hline F150 & Selection of data to be converted & 2 \\
\hline F151 & Data accuracy and integrity & 14 \\
\hline F152 & Package selection & 39 \\
\hline F153 & Careful and professional package selection process/modules & 15 \\
\hline F154 & Fit between ERP and business process, information needs and strategic goals/multi-site issues & 15 \\
\hline F155 & Planning the package selection process & 2 \\
\hline F156 & Software development & 4 \\
\hline F157 & Developing a plan for testing interfaces with integrated legacy systems & 8 \\
\hline F158 & Developing proper troubleshooting tools /Troubleshooting/crises management & 18 \\
\hline F159 & $\begin{array}{l}\text { Robustness and Error Prevention (Working closely with vendors and consultants to resolve software } \\
\text { problems and troubleshooting errors) }\end{array}$ & 6 \\
\hline F160 & Developing proper troubleshooting skills and techniques for the IT workers & 4 \\
\hline F161 & Planning and Establishing Software development, testing and troubleshooting architecture & 17 \\
\hline F162 & $\begin{array}{l}\text { Appropriate modelling methods and Techniques (pre-implementation analysis) / Necessary } \\
\text { preconditions }\end{array}$ & 12 \\
\hline F163 & Configuration of overall ERP architecture & 7 \\
\hline F164 & Monitoring management & 28 \\
\hline F165 & Monitoring and evaluation of performance metrics (fast effects) & 31 \\
\hline F166 & Monitoring progress against clear milestones & 4 \\
\hline F167 & User support organization and involvement & 8 \\
\hline F168 & User friendliness, Help, and Documentation/Document ERP success & 5 \\
\hline F169 & $\begin{array}{l}\text { User acceptance feedback management/Analysis of user feedback (user satisfaction/satisfaction and } \\
\text { system satisfaction) }\end{array}$ & 21 \\
\hline F170 & Enforce project timeliness /Timeframe & 12 \\
\hline F171 & Coordinate project activities & 1 \\
\hline F172 & Track milestones and targets & 3 \\
\hline F173 & Implementation experience/ with ERP implementation in similar scope & 3 \\
\hline F174 & Appropriate business and legacy systems including building a business case & 23 \\
\hline F175 & Post-implementation evaluation/audit & 10 \\
\hline F176 & Client consultation & 8 \\
\hline F177 & Social influence & 1 \\
\hline F178 & Availability of reliable data networks & 3 \\
\hline F179 & standardization and process measurement & 5 \\
\hline F180 & Follow the PDCA cycle & 1 \\
\hline F181 & System’s Response Time to Users' Requests & 1 \\
\hline F182 & Interest/users groups & 2 \\
\hline F183 & Policies and Standards/ Government policies/Model & 4 \\
\hline F184 & Availability of applications (as result of Obsolescence of Hardware and Software) & 1 \\
\hline F185 & Discipline/Base point analysis; Process discipline; benchmarking & 7 \\
\hline F186 & Contingency plans (Co-ordinated analysis; contingency plans) & 3 \\
\hline F187 & Effective management techniques & 2 \\
\hline F188 & Controlled ROI on ERP implementation & 2 \\
\hline F189 & Operational Efficiency & 1 \\
\hline F190 & Internal readiness & 2 \\
\hline F191 & security of interface & 4 \\
\hline
\end{tabular}




\begin{tabular}{|l|l|l|}
\hline F192 & $\begin{array}{l}\text { Integrated department and solve the problem of human resources management/Allocation of Best } \\
\text { Internal Business Personnel }\end{array}$ & 9 \\
\hline F193 & Cost of update/upgrade/maintenance and integration & 3 \\
\hline F194 & Confidentiality & 1 \\
\hline F195 & Feasibility /evaluation of ERP project & 1 \\
\hline F196 & Strategic initiatives & 2 \\
\hline F197 & stimuli (environmental and customer needs) & 3 \\
\hline F198 & ERP treated as a program not a project & 1 \\
\hline F199 & Technical task and tools/Factors & 4 \\
\hline F200 & Reporting structure (project manager reporting to mgmt. & \\
\hline F201 & Required Organizational Buy-In and Project Ownership & 2 \\
\hline F202 & Value Chain Connectivity & 2 \\
\hline F203 & IT provider and Integrator Push & 2 \\
\hline F204 & Globalization & 2 \\
\hline F205 & Procurement Management & 1 \\
\hline
\end{tabular}

TABLE SII. COMPARATIVE RESUlts PCS OF THE CSF WITH RESPECT TO WEKA AND SPSS

\begin{tabular}{|c|c|c|c|c|c|c|c|c|c|c|c|}
\hline \multirow{2}{*}{\multicolumn{8}{|c|}{$\begin{array}{l}\text { WEKA } 66 \text { Principal Components } \\
\text { Initial Eigenvalue }\end{array}$}} & \multicolumn{4}{|c|}{ SPSS 49 Principal Components } \\
\hline & & & & & & & & \multirow[b]{2}{*}{$\begin{array}{l}\text { Componen } \\
\mathrm{t}\end{array}$} & \multicolumn{3}{|c|}{ Initial Eigenvalues } \\
\hline $\begin{array}{l}\text { Principal } \\
\text { Componen } \\
\mathrm{t}\end{array}$ & $\begin{array}{l}\text { eigenvalu } \\
\text { e }\end{array}$ & $\begin{array}{l}\text { proportio } \\
\text { n }\end{array}$ & $\begin{array}{l}\text { cumulativ } \\
\mathrm{e}\end{array}$ & $\begin{array}{l}\text { Principal } \\
\text { Componen } \\
\mathrm{t}\end{array}$ & $\begin{array}{l}\text { eigenvalu } \\
\mathrm{e}\end{array}$ & $\begin{array}{l}\text { proportio } \\
\mathrm{n}\end{array}$ & $\begin{array}{l}\text { cumulativ } \\
\text { e }\end{array}$ & & $\begin{array}{l}\text { Eigen- } \\
\text { value }\end{array}$ & $\begin{array}{l}\text { \% of } \\
\text { Varianc } \\
\text { e }\end{array}$ & $\begin{array}{l}\text { Cumulativ } \\
\text { e \% }\end{array}$ \\
\hline PC1 & 28.01467 & 0.13666 & 0.13666 & PC50 & 0.96216 & 0.00469 & 0.89668 & PC1 & $\begin{array}{l}28.01 \\
5 \\
\end{array}$ & 13.666 & 13.666 \\
\hline PC2 & 11.74692 & 0.05730 & 0.19396 & PC51 & 0.95278 & 0.00465 & 0.90133 & PC2 & $\begin{array}{l}11.74 \\
7\end{array}$ & 5.730 & 19.396 \\
\hline PC3 & 10.75159 & 0.05245 & 0.24641 & PC52 & 0.88444 & 0.00431 & 0.90564 & PC3 & $\begin{array}{l}10.75 \\
2\end{array}$ & 5.245 & 24.641 \\
\hline PC4 & 9.78366 & 0.04773 & 0.29413 & PC53 & 0.86610 & 0.00422 & 0.90987 & PC4 & 9.784 & 4.773 & 29.413 \\
\hline PC5 & 8.41872 & 0.04107 & 0.33520 & PC54 & 0.83310 & 0.00406 & 0.91393 & PC5 & 8.419 & 4.107 & 33.520 \\
\hline PC6 & 7.02066 & 0.03425 & 0.36944 & PC55 & 0.79243 & 0.00387 & 0.91780 & PC6 & 7.021 & 3.425 & 36.944 \\
\hline PC7 & 5.46663 & 0.02667 & 0.39611 & PC56 & 0.77909 & 0.00380 & 0.92160 & PC7 & 5.467 & 2.667 & 39.611 \\
\hline PC8 & 5.19389 & 0.02534 & 0.42145 & PC57 & 0.74995 & 0.00366 & 0.92526 & PC8 & 5.194 & 2.534 & 42.145 \\
\hline PC9 & 4.97628 & 0.02427 & 0.44572 & PC58 & 0.70508 & 0.00344 & 0.92870 & PC9 & 4.976 & 2.427 & 44.572 \\
\hline PC10 & 4.71714 & 0.02301 & 0.46873 & PC59 & 0.67867 & 0.00331 & 0.93201 & PC10 & 4.717 & 2.301 & 46.873 \\
\hline PC11 & 4.44978 & 0.02171 & 0.49044 & PC60 & 0.65077 & 0.00317 & 0.93518 & PC11 & 4.450 & 2.171 & 49.044 \\
\hline PC12 & 4.38653 & 0.02140 & 0.51184 & PC61 & 0.62464 & 0.00305 & 0.93823 & PC12 & 4.387 & 2.140 & 51.184 \\
\hline PC13 & 4.18899 & 0.02043 & 0.53227 & PC62 & 0.60563 & 0.00295 & 0.94118 & PC13 & 4.189 & 2.043 & 53.227 \\
\hline PC14 & 3.77951 & 0.01844 & 0.55071 & PC63 & 0.59025 & 0.00288 & 0.94406 & PC14 & 3.780 & 1.844 & 55.071 \\
\hline PC15 & 3.76175 & 0.01835 & 0.56906 & PC64 & 0.57522 & 0.00281 & 0.94687 & PC15 & 3.762 & 1.835 & 56.906 \\
\hline PC16 & 3.55745 & 0.01735 & 0.58641 & PC65 & 0.54523 & 0.00266 & 0.94953 & PC16 & 3.557 & 1.735 & 58.641 \\
\hline PC17 & 3.32842 & 0.01624 & 0.60265 & PC66 & 0.51769 & 0.00253 & 0.95205 & PC17 & 3.328 & 1.624 & 60.265 \\
\hline PC18 & 3.22817 & 0.01575 & 0.61839 & & & & & PC18 & 3.228 & 1.575 & 61.839 \\
\hline PC19 & 3.03787 & 0.01482 & 0.63321 & & & & & PC19 & 3.038 & 1.482 & 63.321 \\
\hline PC20 & 3.00068 & 0.01464 & 0.64785 & & & & & PC20 & 3.001 & 1.464 & 64.785 \\
\hline PC21 & 2.90889 & 0.01419 & 0.66204 & & & & & PC21 & 2.909 & 1.419 & 66.204 \\
\hline PC22 & 2.75999 & 0.01346 & 0.67550 & & & & & PC22 & 2.760 & 1.346 & 67.550 \\
\hline PC23 & 2.59826 & 0.01267 & 0.68818 & & & & & PC23 & 2.598 & 1.267 & 68.818 \\
\hline PC24 & 2.44134 & 0.01191 & 0.70009 & & & & & PC24 & 2.441 & 1.191 & 70.009 \\
\hline PC25 & 2.40218 & 0.01172 & 0.71180 & & & & & PC25 & 2.402 & 1.172 & 71.180 \\
\hline PC26 & 2.23643 & 0.01091 & 0.72271 & & & & & PC26 & 2.236 & 1.091 & 72.271 \\
\hline PC27 & 2.15058 & 0.01049 & 0.73320 & & & & & PC27 & 2.151 & 1.049 & 73.320 \\
\hline PC28 & 2.13079 & 0.01039 & 0.74360 & & & & & PC28 & 2.131 & 1.039 & 74.360 \\
\hline PC29 & 2.05022 & 0.01000 & 0.75360 & & & & & PC29 & 2.050 & 1.000 & 75.360 \\
\hline PC30 & 1.98248 & 0.00967 & 0.76327 & & & & & РC30 & 1.982 & 0.967 & 76.327 \\
\hline PC31 & 1.84063 & 0.00898 & 0.77225 & & & & & PC31 & 1.841 & 0.898 & 77.225 \\
\hline PC32 & 1.83486 & 0.00895 & 0.78120 & & & & & PC32 & 1.835 & 0.895 & 78.120 \\
\hline PC33 & 1.79143 & 0.00874 & 0.78994 & & & & & PC33 & 1.791 & 0.874 & 78.994 \\
\hline
\end{tabular}




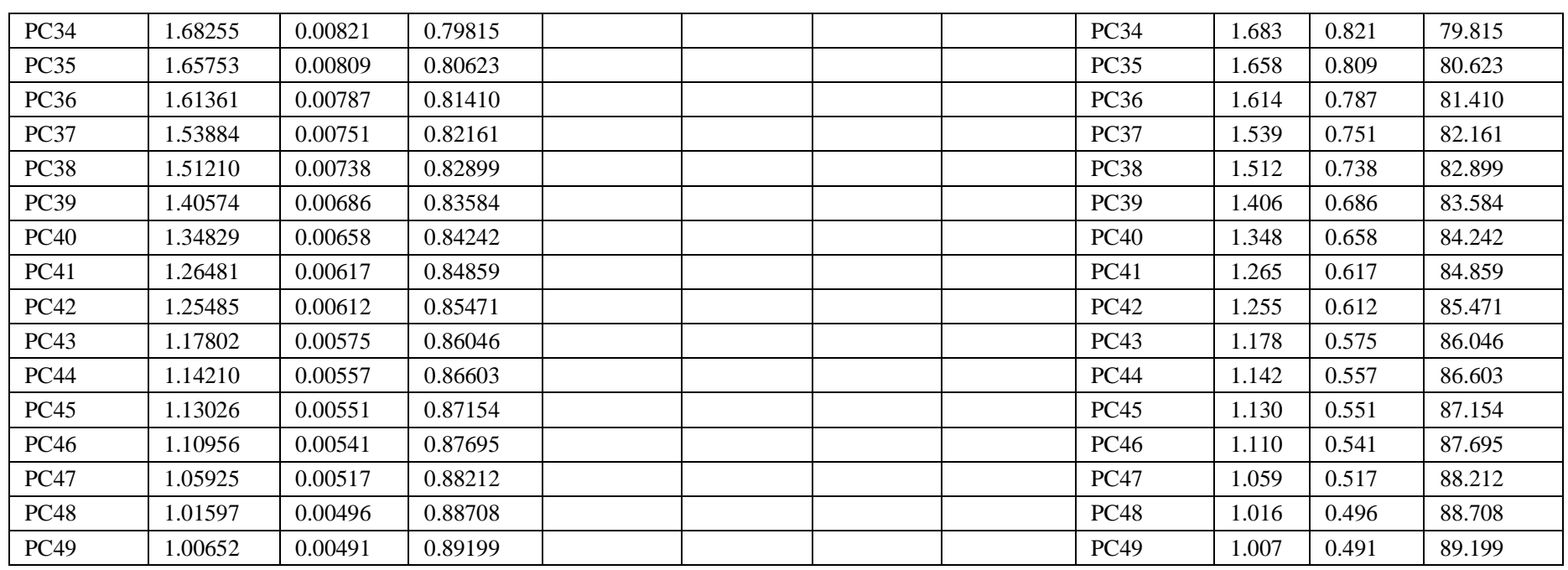

TABLE SIII. RANK ATTRIBUTES WITH 5 FACTOR LOADINGS

\begin{tabular}{|c|c|c|}
\hline Ranked & Attributes & Contribution \\
\hline 0.8633 & 1 & $0.166 \mathrm{~F} 81+0.166 \mathrm{~F} 37+0.166 \mathrm{~F} 146+0.166 \mathrm{~F} 32+0.166 \mathrm{~F} 60 \ldots$ \\
\hline 0.806 & 2 & $0.205 \mathrm{~F} 118+0.193 \mathrm{~F} 133+0.189 \mathrm{~F} 178+0.169 \mathrm{~F} 13+0.162 \mathrm{~F} 132 \ldots$ \\
\hline 0.7536 & 3 & $\begin{array}{l}-0.213 F 128-0.213 F 181-0.213 F 184-0.162 F 182+0.157 F 17 \ldots \\
\end{array}$ \\
\hline 0.7059 & 4 & $-0.169 F 149+0.165 F 177-0.161 F 88+0.159 F 125+0.159 F 20 \ldots$ \\
\hline 0.6648 & 5 & $\begin{array}{c}-0.195 F 17-0.195 F 171-0.172 F 18-0.172 F 109+0.168 F 137 \ldots \\
\end{array}$ \\
\hline 0.6306 & 6 & 0.25 F95-0.205F77-0.204F175+0.2F82+0.184F97 ... \\
\hline 0.6039 & 7 & $\begin{array}{l}-0.212 F 72-0.18 F 65-0.178 F 9-0.178 F 67-0.177 F 105 \ldots \\
\end{array}$ \\
\hline 0.5786 & 8 & $0.232 \mathrm{~F} 196+0.203 \mathrm{~F} 98+0.196 \mathrm{~F} 205+0.191 \mathrm{~F} 63-0.17 \mathrm{~F} 203 \ldots$ \\
\hline 0.5543 & 9 & $-0.23 \mathrm{~F} 55-0.181 \mathrm{~F} 112-0.175 \mathrm{~F} 123+0.168 \mathrm{~F} 203+0.168 \mathrm{~F} 202 \ldots$ \\
\hline 0.5313 & 10 & $0.202 F 11+0.191 F 73+0.187 F 55+0.184 F 26+0.176 F 83 \ldots$ \\
\hline 0.5096 & 11 & $\begin{array}{c}-0.202 F 203-0.202 F 202+0.198 F 22+0.176 F 104-0.169 F 154 \ldots \\
.\end{array}$ \\
\hline 0.4882 & 12 & $0.194 F 2-0.182 F 180+0.18$ F1-0.178F126+0.176F104... \\
\hline 0.4677 & 13 & $0.216 \mathrm{~F} 127+0.199 \mathrm{~F} 197+0.188 \mathrm{~F} 112+0.185 \mathrm{~F} 113+0.184 \mathrm{~F} 86 \ldots$ \\
\hline 0.4493 & 14 & $\begin{array}{c}-0.225 F 201-0.213 F 160-0.203 F 105-0.198 F 200-0.194 F 34 \ldots \\
\end{array}$ \\
\hline 0.4309 & 15 & $\begin{array}{l}-0.272 F 130-0.184 F 63-0.182 F 135-0.179 F 16-0.173 F 22 \ldots \\
\end{array}$ \\
\hline 0.4136 & 16 & $0.203 \mathrm{~F} 173+0.193 \mathrm{~F} 180+0.186 \mathrm{~F} 69+0.166 \mathrm{~F} 191+0.166 \mathrm{~F} 162 .$. \\
\hline 0.3974 & 17 & $\begin{array}{l}-0.195 F 90+0.186 F 4-0.18 F 162-0.177 F 194+0.17 \text { F80... } \\
\end{array}$ \\
\hline 0.3816 & 18 & $0.308 \mathrm{~F} 69+0.219 \mathrm{~F} 157+0.218 \mathrm{~F} 70-0.212 \mathrm{~F} 64-0.212 \mathrm{~F} 86 \ldots$ \\
\hline 0.3668 & 19 & $0.225 \mathrm{~F} 179+0.223 \mathrm{~F} 180+0.197 \mathrm{~F} 186+0.189 \mathrm{~F} 122-0.172 \mathrm{~F} 111 .$. \\
\hline 0.3521 & 20 & 0.232F189-0.189F64-0.189F86+0.173F39+0.172F28... \\
\hline 0.338 & 21 & $0.225 F 170-0.209 F 168+0.208 F 204+0.201 F 46-0.2 F 186 \ldots$ \\
\hline 0.3245 & 22 & 0.258F33-0.19F194-0.179F75+0.173F71+0.163F26... \\
\hline 0.3118 & 23 & $0.242 \mathrm{~F} 197+0.227 \mathrm{~F} 189+0.173 \mathrm{~F} 190+0.171 \mathrm{~F} 174+0.161 \mathrm{~F} 12 \ldots$ \\
\hline 0.2999 & 24 & $-0.263 F 52+0.198 F 89+0.193 F 167-0.192 F 204+0.188 F 129 \ldots$ \\
\hline 0.2882 & 25 & $\begin{array}{l}-0.236 F 194-0.21 F 204-0.208 F 131-0.206 F 193+0.176 F 38 \ldots \\
\end{array}$ \\
\hline 0.2773 & 26 & 0.3 F33-0.2F8-0.178F110+0.167F175+0.166F187... \\
\hline 0.2668 & 27 & 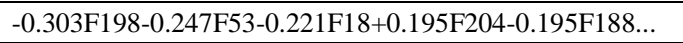 \\
\hline 0.2564 & 28 & 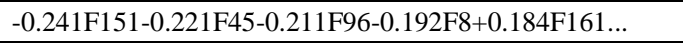 \\
\hline 0.2464 & 29 & $0.235 F 191+0.22$ F198-0.207F10-0.202F62+0.192F124... \\
\hline 0.2367 & 30 & $-0.193 F 131-0.178 F 136-0.172 F 45-0.151 F 124-0.151 F 10 \ldots$ \\
\hline 0.2278 & 31 & $-0.404 F 198-0.208 F 188-0.195 F 18+0.172 F 193+0.162 F 194 \ldots$ \\
\hline 0.2188 & 32 & 0.224F204-0.216F192-0.203F174-0.184F164+0.164F63... \\
\hline 0.2101 & 33 & $-0.226 F 88+0.217 F 25+0.193 F 205+0.177 F 111+0.174 F 136 \ldots$ \\
\hline 0.2019 & 34 & $-0.263 F 183+0.241 F 79+0.179 F 66-0.175 F 62-0.168 F 177 \ldots$ \\
\hline 0.1938 & 35 & $0.219 F 23-0.216 F 62-0.21 F 126+0.2$ F11+0.18 F51... \\
\hline 0.1859 & 36 & $0.252 F 9+0.212 F 27+0.211 F 52-0.186 F 198+0.18$ F172... \\
\hline
\end{tabular}




\begin{tabular}{|c|c|c|}
\hline 0.1784 & 37 & $0.274 \mathrm{~F} 195+0.239 \mathrm{~F} 192+0.229 \mathrm{~F} 8-0.175 \mathrm{~F} 35-0.161 \mathrm{~F} 108 \ldots$ \\
\hline 0.171 & 38 & $-0.208 \mathrm{~F} 110+0.188 \mathrm{~F} 72+0.181 \mathrm{~F} 43+0.172 \mathrm{~F} 198-0.168 \mathrm{~F} 89 \ldots$ \\
\hline 0.1642 & 39 & 0.268F192-0.259F151-0.221F135+0.203F29-0.18F63... \\
\hline 0.1576 & 40 & 0.391F195-0.21F205+0.2 F71+0.182F10+0.18 F105... \\
\hline 0.1514 & 41 & -0.192F195+0.191F176-0.189F15+0.185F108+0.167F29... \\
\hline 0.1453 & 42 & $0.329 F 7+0.243 F 96+0.207 F 158+0.204 \mathrm{~F} 172+0.188 \mathrm{~F} 38 \ldots$ \\
\hline 0.1395 & 43 & $-0.182 F 29+0.175 F 183+0.173 F 28+0.167 F 135-0.156 F 80 \ldots$ \\
\hline 0.134 & 44 & 0.391F195-0.256F144-0.215F201-0.2F80-0.19F154... \\
\hline 0.1285 & 45 & $-0.242 F 108-0.228 F 27-0.227 F 172+0.225 F 191+0.167 F 59 \ldots$ \\
\hline 0.123 & 46 & $\begin{array}{l}-0.251 F 96-0.194 F 161-0.189 F 168+0.181 F 164-0.178 F 91 \ldots \\
\end{array}$ \\
\hline 0.1179 & 47 & $0.265 \mathrm{~F} 200+0.221 \mathrm{~F} 163+0.214 \mathrm{~F} 27+0.201 \mathrm{~F} 195-0.196 \mathrm{~F} 66 \ldots$ \\
\hline 0.1129 & 48 & -0.34F101-0.219F115+0.204F7-0.192F78-0.176F163... \\
\hline 0.108 & 49 & $-0.239 F 91-0.227 F 190-0.219 F 16-0.208 F 108-0.185 F 195 \ldots$ \\
\hline 0.1033 & 50 & $-0.289 F 186-0.219 F 103+0.202 F 66+0.201 \mathrm{~F} 19+0.183 \mathrm{~F} 45 \ldots$ \\
\hline 0.0987 & 51 & $-0.383 F 1+0.228 F 195-0.211 F 199+0.172 F 201-0.172 F 98 \ldots$ \\
\hline 0.0944 & 52 & $-0.203 F 52+0.202 F 110+0.177 F 205-0.176 F 34-0.171 F 41 \ldots$ \\
\hline 0.0901 & 53 & $-0.242 \mathrm{~F} 101+0.242 \mathrm{~F} 1+0.225 \mathrm{~F} 115-0.169 \mathrm{~F} 23-0.16 \mathrm{~F} 195 \ldots$ \\
\hline 0.0861 & 54 & $0.246 F 42-0.225 F 101+0.215 F 176+0.21$ F57+0.172F103... \\
\hline 0.0822 & 55 & $0.232 \mathrm{~F} 45+0.217 \mathrm{~F} 143-0.206 \mathrm{~F} 168+0.201 \mathrm{~F} 1+0.163 \mathrm{~F} 7 \ldots$ \\
\hline 0.0784 & 56 & $-0.218 \mathrm{~F} 140+0.186 \mathrm{~F} 127+0.18 \mathrm{~F} 169-0.18 \mathrm{~F} 168+0.171 \mathrm{~F} 119 \ldots$ \\
\hline 0.0747 & 57 & 0.202F68+0.202F154-0.178F1+0.166F2-0.156F195... \\
\hline 0.0713 & 58 & $-0.253 \mathrm{~F} 112+0.221 \mathrm{~F} 107-0.219 \mathrm{~F} 113-0.191 \mathrm{~F} 144+0.189 \mathrm{~F} 8 \ldots$ \\
\hline 0.068 & 59 & $0.202 F 152+0.2$ F83+0.188F38-0.178F71-0.178F25... \\
\hline 0.0648 & 60 & 0.187F74+0.175F105-0.171F157-0.17F96-0.161F136... \\
\hline 0.0618 & 61 & $-0.241 \mathrm{~F} 107-0.231 \mathrm{~F} 89+0.225 \mathrm{~F} 8+0.202 \mathrm{~F} 122+0.159 \mathrm{~F} 172 \ldots$ \\
\hline 0.0588 & 62 & $-0.203 F 43+0.187 F 2+0.183 F 106+0.177 F 71+0.17$ F82 $\ldots$ \\
\hline 0.0559 & 63 & 0.21 F46+0.202F29-0.194F115-0.18F25+0.172F91... \\
\hline 0.0531 & 64 & $-0.308 F 167+0.207 F 194-0.183 F 144-0.178 F 23-0.177 F 135 \ldots$ \\
\hline 0.0505 & 65 & 0.271F76+0.253F43+0.199F144+0.197F151-0.166F35... \\
\hline 0.0479 & 66 & $-0.209 F 122-0.187 F 21-0.184 F 63-0.182 F 91-0.178 F 101 \ldots$ \\
\hline
\end{tabular}

